\title{
Risk of contralateral second primary breast cancer according to hormone receptor status in Germany
}

\author{
Carsten Rusner ${ }^{1 * \dagger}$, Katharina Wolf ${ }^{1 \dagger}$, Ulrike Bandemer-Greulich ${ }^{2}$, Jutta Engel ${ }^{3}$, Christa Stegmaier ${ }^{4}$, Bernd Holleczek ${ }^{4}$, \\ Gabriele Schubert-Fritschle ${ }^{3}$, Anett Tillack ${ }^{2}$ and Andreas Stang ${ }^{1,5}$
}

\begin{abstract}
Introduction: Hormone receptor (HR) status has become an established target in treatment strategies of breast cancer. Population-based estimates of contralateral breast cancer (CBC) incidence by HR subtype in particular are limited. The aim of this study was to provide detailed data on CBC incidence for Germany.

Methods: Invasive breast cancer data were extracted on 49,804 women yielding 594 second primaries from the cancer registries of the Federal States of Brandenburg and Saarland and the area of Munich for the period from 1998 to 2007. Multiple imputation was used on missing values for HR status. We estimated standardized incidence ratios (SIRs) with 95\% confidence intervals (95\%Cls).
\end{abstract}

Results: SIR estimates of CBC among women diagnosed with an invasive first primary breast cancer (FBC) of any HR subtype ranged from 1.0 to 1.5 in the three registries. Pooling three registries' data, the SIR of HR-positive CBC was 0.7 ( $95 \% \mathrm{Cl}$ : 0.6 to 0.8) among women with HR-positive FBC. For those women with HR-negative FBC, the SIR of HR-negative CBC was 8.9 (95\%Cl: 7.1 to 11.1). Among women with FBC diagnosed before the age of 50 years, incidence of CBC was increased, especially for HR-negative FBC (SIR: 9.2; 95\%Cl: 7.1 to 11.9).

Conclusions: HR status of the first primary and age at first diagnosis is relevant for predicting risk of CBC. Particularly, patients with HR-negative FBC had elevated risks.

\section{Introduction}

Prognosis of breast cancer has improved over the recent decades by progress in diagnosis and treatment [1]. However, patients with breast cancer have an increased risk of developing a new primary breast cancer in the contralateral breast. Family history of breast cancer, early age at diagnosis, characteristics of the first primary (for example lobular histology and stage) and mutations in specific genes, including BRCA1, BRCA2 and CHEK2, are considered as risk factors [2,3]. Hormone receptor (HR) status of breast cancer is also a relevant factor, in particular with regard to treatment decisions and further prognosis. Treatment strategies of radiotherapy and chemotherapy after surgery of HR-positive breast cancer are

\footnotetext{
* Correspondence: carsten.rusner@medizin.uni-halle.de

${ }^{\dagger}$ Equal contributors

'Institute of Clinical Epidemiology, Medical Faculty, Martin-Luther-University of Halle-Wittenberg, Magdeburger Strasse 8, 06097 Halle (Saale), Germany Full list of author information is available at the end of the article
}

followed by an adjuvant hormonal treatment. Hormone treatment with tamoxifen or aromatase inhibitor anastrozole for reducing the risk of contralateral breast cancer $(\mathrm{CBC})$ is well known. A meta-analysis of 55 randomized trials found that use of tamoxifen for five years reduces the risk of CBC by $47 \%$ [4]. There is some evidence that tamoxifen treatment may increase the risk of HR-negative $\mathrm{CBC}$ [5].

Only few population-based reports showed the impact of HR subtype in invasive first primary breast cancers (FBC) on risk of $\mathrm{CBC}$. Three previously published studies reported an increased risk of HR-negative $\mathrm{CBC}$ after HRnegative $\mathrm{FBC}$. Results of developing $\mathrm{CBC}$ after HR-positive FBC were contradictory [6-8].

The aim of our study was to provide detailed estimates of $\mathrm{CBC}$ incidence according to HR status of FBC using data from population-based cancer registries in Germany. This study also focused on mixed HR status, which has not been presented by previous studies. 


\section{Methods}

Female patients diagnosed with FBC were identified in the population-based cancer registries of the Federal States of Saarland and Brandenburg and in the Munich Cancer Registry for the period 1998 to 2007. Ethical approval for this study was not required because we used anonymized data of cancer registries for scientific purposes according to Good Practice for Secondary Data Analysis [9].

The cancer registry of the Federal State of Brandenburg (BB) was established in 1993 and comprises five hospitalbased cancer registries covering the entire territory of the Federal State. The Munich Cancer Registry (MCR) was established in 1978 and routinely records data for all cancer patients treated in Munich and the surrounding area. It receives clinical data from 73 hospitals and several hundred doctors in private practice. The Saarland Cancer Registry (SL) is a population-based cancer registry and covers the entire territory of the Federal State of Saarland. The registry was established in 1967. The three registries comprise a population of 6.9 million in total (BB: 2.6, MCR: 3.3, SL: 1.1 million). BB, MCR and SL have been involved in several regional, national and international research collaborations [10]. The registries provide cancer incidence data with an estimated completeness of $90 \%$ and more [11]. However, the completeness of HR status registration was too low for a meaningful data analysis until 1998 because German cancer registries do not routinely collect or receive data of hormone receptor status. A special data collection effort from available pathology reports in all three registries allowed us to obtain HR status information for the specified years of 1998 to 2007. For the remaining cases with missing information on HR status, we re-contacted the reporting pathologists.

Invasive breast cancers were coded as C50 according to the 10th edition of the International Classification of Diseases, respectively (ICD-10) [12]. For additional analyses, we defined four major histologic groups of breast cancer: invasive ductal (8500/3, 8503/3, 8521/3, 8525/3), invasive lobular (8520/3), invasive ductal and lobular mixed (8522-8524/3, 8541/3) carcinomas, and cancers of other or unspecified (8000/3-8004/3) histologic type based on the $3^{\text {rd }}$ edition of the International Classification of Diseases for Oncology (ICD-O-3) [13]. All patients with FBC were followed from the date of diagnosis until detection of a second primary cancer in the contralateral breast, death, loss to follow-up or until 31 December 2007, whichever of these events came first. Invasive primary cancers occurring six months after diagnosis of the FBC were defined as metachronous tumors. Cancers occurring earlier than six months were considered as synchronous tumors and were excluded from analyses. Information on human epidermal growth factor receptor 2 (HER2) amplification, stage at time of diagnosis and treatment was too frequently missing for a meaningful data analysis.

Table 1 presents an overview of the analyzed FBC cases in the registries. The proportion of histological verification of FBC was generally high with a range of 92.5 to $96.8 \%$ and for cases of metachronous primary breast cancer with up to $100 \%$ confirmation. The proportion of missing HR status information (estrogen receptor (ER) or progesterone receptor (PR)) in FBC ranged between 7.0 and $15.1 \%$. SL did not routinely collect HR status of $\mathrm{CBC}$, which was reflected in a greater proportion of missing information. Pooling three registries' data, the median follow-up period for FBC was approximately just three years. The cohort yielded a total of 180,768 personyears of observation. We defined the following categories of HR subtype: positive (ER+ PR+), negative (ER-PR-) and mixed (ER+ PR- or ER-PR+).

\section{Statistical methods}

As simulation studies previously showed that analyses using completed data sets derived from multiple imputation tend to provide less biased estimates compared to complete case analyses, we used multiple imputation of HR status to account for missing data $[14,15]$. We assumed missingness at random and included date of diagnosis, date of birth, duration of follow-up, region code and diagnosis confirmation as additional clinical items for the imputation. We imputed 20 times applying PROC MI of SAS $^{\mathrm{rm}}$ (SAS Inc., Cary, NC, USA). The results from these 20 imputed data sets were summarized using Rubin's method [16].

We estimated the standardized incidence ratios (SIRs) of metachronous primary breast cancer to quantify the relative risk of $\mathrm{CBC}$ among women with $\mathrm{FBC}$ compared to the relative risk of developing $\mathrm{FBC}$ in the general population. The SIR was obtained as the ratio of the number of observed cases $(\mathrm{O})$ to the number of expected cases (E). E was calculated by multiplying accumulated person-years at risk after $\mathrm{FBC}$ and cancer incidence rates specific for sex (female), age (0 to 4,5 to $9, \ldots, 80$ to 84 , $85+$ years), five-year calendar period and the respective registry. Corresponding 95\% confidence intervals (95\% CIs) were based on the Poisson distribution. To obtain more precise SIR estimates of metachronous primary breast cancers, we pooled the case files and corresponding person-years at risk of the registries.

\section{Results}

A total of 594 new CBCs among 49,804 women diagnosed with $\mathrm{FBC}$ were registered in the three populations from 1998 through 2007. The SIRs of CBC among women with FBC of any HR subtype ranged from 1.0 in MCR to 1.5 in $\mathrm{BB}$ (Table 2). In all three registries, among women with HR-positive FBC, risk of HR-positive CBC was lower 
Table 1 Baseline characteristics of invasive breast cancer of analyzed cancer registries in Germany, 1998 to 2007

\begin{tabular}{|c|c|c|c|c|}
\hline & Brandenburg & Munich & Saarland & Pooled \\
\hline Registered cases of invasive first primary breast cancer (n) & 15,226 & 26,315 & 8,263 & 49,804 \\
\hline Histological verification (\%) & 94.6 & 92.5 & 96.8 & 93.8 \\
\hline \multicolumn{5}{|l|}{ Receptor status information (\%) } \\
\hline Estrogen positive & 72.1 & 72.6 & 69.0 & 71.9 \\
\hline negative & 20.9 & 13.5 & 16.0 & 16.2 \\
\hline missing & 7.0 & 13.9 & 15.0 & 11.9 \\
\hline Progesterone positive & 66.6 & 68.8 & 61.0 & 66.9 \\
\hline negative & 26.1 & 17.0 & 23.9 & 20.9 \\
\hline missing & 7.3 & 14.2 & 15.1 & 12.2 \\
\hline Median (IQR) age at diagnosis of first primary breast cancer & $63(52-72)$ & $63(53-73)$ & $64(54-74)$ & $63(53-73)$ \\
\hline Person-years of observation & 57,108 & 92,247 & 31,413 & 180,768 \\
\hline Median (IQR) years of follow-up & $3.3(1.3-5.9)$ & $3.0(1.1-5.4)$ & $3.4(1.3-6.0)$ & $3.1(1.2-5.7)$ \\
\hline Registered cases of metachronous contralateral breast cancer (n) & 185 & 287 & 122 & 594 \\
\hline Histological verification (\%) & 98.4 & 100.0 & 99.2 & 99.3 \\
\hline \multicolumn{5}{|l|}{ Receptor status information (\%) } \\
\hline Estrogen positive & 53.0 & 61.0 & 37.7 & 53.7 \\
\hline negative & 42.7 & 27.2 & 19.7 & 30.5 \\
\hline missing & 4.3 & 11.8 & 42.6 & 15.8 \\
\hline Progesterone positive & 44.3 & 53.3 & 27.9 & 45.3 \\
\hline negative & 51.4 & 34.8 & 29.5 & 38.9 \\
\hline missing & 4.3 & 11.8 & 42.6 & 15.8 \\
\hline
\end{tabular}

IQR: interquartile range.

compared to the risk of developing $\mathrm{FBC}$ in the general population. Conversely, those with HR-negative FBC had in particular an increased risk of HR-negative CBC. SIR estimates for HR-mixed second primary after HR-mixed FBC were elevated in all three registries. Table 2 shows subtype-specific SIRs for the registries that include at least five cases in total. In sensitivity analyses, where we only distinguished between ER-positive and ER-negative regardless of the PR subtype or excluded cases with missing HR status to assess whether imputation affected SIRs, estimates were similar (Table S1 and Table S2 in Additional file 1).

Pooling three registries' data, the SIR of HR-positive CBC was 0.9 (95\%CI: 0.8 to 1.0). Particularly, among women with HR-positive FBC the SIR was 0.7 (95\%CI: 0.6 to 0.8$)$. In contrast, women with FBC of any HR subtype showed an increased estimate of HR-negative CBC (SIR: 2.5; 95\%CI: 2.1 to 2.9). Especially, an almost ninefold markedly elevated incidence of $\mathrm{CBC}$ was observed when FBC was HR-negative (SIR: 8.9; 95\%CI: 7.1 to 11.1). Among patients with HR-mixed FBC risk of HRmixed CBC was increased (SIR: 4.2; 95\%CI: 2.8 to 5.9). Considering a greater proportion of missing HR status information of $\mathrm{CBC}$ in SL, we restricted the pooling to
$\mathrm{BB}$ and MCR for sensitivity. In this analysis, estimates remained similar (results not shown).

According to the HR status and age at first cancer diagnosis (Table 3), for women aged lower than 50 years with HR-positive FBC, SIR of HR-positive CBC was 1.7 (95\%CI: 1.2 to 2.5 ) while in women aged 50 years and older that risk was lower (SIR: 0.6 ; $95 \%$ CI: 0.5 to 0.7 ) compared to the risk of developing $\mathrm{FBC}$ in the general population. We observed exceedingly pronounced risks of $\mathrm{CBC}$ for women with HR-negative $\mathrm{FBC}$ diagnosed before the age of 50 years (SIR: 9.2; 95\%CI: 7.1 to 11.9). Regarding these patients, the risk of HR-negative CBC was approximately 10 times higher than that one of HR-positive CBC.

A histology-specific analysis of $\mathrm{FBC}$ revealed that estimates of HR-positive CBCs were similar: ductal (SIR: 0.8; $95 \%$ CI: 0.7 to 0.9 ); lobular (SIR: 0.9 ; $95 \%$ CI: 0.7 to 1.2). The estimated SIR for HR-negative CBC was higher in invasive ductal (SIR: 2.7; 95\%CI: 2.3 to 3.2) than in invasive lobular (SIR: 1.6; 95\%CI: 0.9 to 2.6) FBCs.

\section{Discussion}

We showed by German population-based data that the incidence of a subsequent $\mathrm{CBC}$ was modified by $\mathrm{HR}$ 
Table 2 Standardized incidence ratios of metachronous contralateral breast cancer stratified by hormone receptor (HR)-status in Brandenburg, Munich and Saarland, 1998 to 2007

\begin{tabular}{|c|c|c|c|c|c|c|c|c|c|c|c|c|}
\hline & Brande & burg & & Municl & & & Saarla & & & Pooled & & \\
\hline & 0 & SIR & $95 \% \mathrm{Cl}$ & $\overline{0}$ & SIR & $95 \% \mathrm{Cl}$ & 0 & SIR & $95 \% \mathrm{Cl}$ & $\overline{0}$ & SIR & $95 \% \mathrm{Cl}$ \\
\hline Any first primary & 15,226 & & & 26,315 & & & 8,263 & & & 49,804 & & \\
\hline Any second primary & 185 & 1.5 & $1.3-1.7$ & 287 & 1.0 & $0.9-1.1$ & 122 & 1.4 & $1.2-1.7$ & 594 & 1.2 & $1.1-1.3$ \\
\hline Second primary HR-positive & 71 & 0.9 & $0.7-1.2$ & 137 & 0.8 & $0.6-0.9$ & 33 & 1.1 & $0.9-1.4$ & 241 & 0.9 & $0.8-1.0$ \\
\hline Second primary HR-negative & 68 & 3.3 & $2.6-4.2$ & 62 & 2.1 & $1.6-2.7$ & 23 & 2.3 & $1.5-3.2$ & 153 & 2.5 & $2.1-2.9$ \\
\hline Second primary HR-mixed & 38 & 1.9 & $1.4-2.6$ & 54 & 1.8 & $1.3-2.3$ & 14 & 2.0 & $1.2-2.9$ & 106 & 2.0 & $1.7-2.4$ \\
\hline First primary HR-positive & 9,698 & & & 17,286 & & & 4,880 & & & 31,864 & & \\
\hline Any second primary & 97 & 1.1 & $0.9-1.4$ & 149 & 0.8 & $0.6-0.9$ & 53 & 1.0 & $0.8-1.4$ & 299 & 0.9 & $0.8-1.0$ \\
\hline Second primary HR-positive & 44 & 0.8 & $0.6-1.0$ & 94 & 0.6 & $0.5-0.7$ & 26 & 0.9 & $0.6-1.2$ & 164 & 0.7 & $0.6-0.8$ \\
\hline Second primary HR-negative & 31 & 2.1 & $1.4-3.0$ & 17 & 0.8 & $0.5-1.2$ & 2 & & & 50 & 1.1 & $0.8-1.4$ \\
\hline Second primary HR-mixed & 19 & 1.3 & $0.8-2.0$ & 24 & 1.0 & $0.6-1.5$ & 6 & 1.1 & $0.5-2.1$ & 49 & 1.2 & $0.9-1.6$ \\
\hline First primary HR-negative & 2,731 & & & 2,758 & & & 1,164 & & & 6,653 & & \\
\hline Any second primary & 61 & 3.0 & $2.3-3.9$ & 69 & 2.7 & $2.1-3.4$ & 34 & 3.2 & $2.2-4.5$ & 164 & 2.8 & $2.4-3.3$ \\
\hline Second primary HR-positive & 20 & 1.6 & $1.0-2.4$ & 17 & 1.0 & $0.6-1.5$ & 2 & & & 39 & 1.1 & $0.8-1.5$ \\
\hline Second primary HR-negative & 31 & 8.5 & $5.8-12.0$ & 30 & 8.9 & $6.1-12.7$ & 18 & 9.6 & $5.8-14.9$ & 79 & 8.9 & 7.1-11.1 \\
\hline Second primary HR-mixed & 7 & 2.4 & $1.0-4.8$ & 14 & 4.3 & $2.4-7.1$ & 3 & & & 24 & 3.7 & $2.5-5.2$ \\
\hline First primary HR- mixed & 1,682 & & & 2,524 & & & 969 & & & 5,175 & & \\
\hline Any second primary & 26 & 1.8 & $1.2-2.7$ & 33 & 1.2 & $0.8-1.7$ & 17 & 1.4 & $0.8-2.3$ & 76 & 1.4 & $1.1-1.8$ \\
\hline Second primary HR-positive & 7 & 0.8 & $0.3-1.6$ & 9 & 0.5 & $0.3-0.9$ & 1 & & & 17 & 0.6 & $0.4-0.9$ \\
\hline Second primary HR-negative & 6 & 2.5 & $0.9-5.4$ & 8 & 2.5 & $1.1-4.8$ & 2 & & & 16 & 2.2 & $1.3-3.5$ \\
\hline Second primary HR-mixed & 12 & 5.0 & $2.6-8.7$ & 11 & 3.2 & $1.7-5.7$ & 4 & & & 27 & 4.2 & $2.8-5.9$ \\
\hline
\end{tabular}

O: observed number of cases; SIR: standardized incidence ratio; $95 \% \mathrm{Cl}$ : 95\% confidence interval; HR, hormone receptor.

Table 3 Standardized incidence ratios of metachronous contralateral breast cancer stratified by hormone receptor (HR)-status and age in Brandenburg, Munich and Saarland overall, 1998 to 2007

\begin{tabular}{|c|c|c|c|c|c|c|}
\hline & \multicolumn{3}{|c|}{ Women with first primary age $<50$} & \multicolumn{3}{|c|}{ Women with first primary age $\geq 50$} \\
\hline & 0 & SIR & $95 \% \mathrm{Cl}$ & 0 & SIR & $95 \% \mathrm{Cl}$ \\
\hline Any first primary & 9,684 & & & 40,120 & & \\
\hline Any second primary & 144 & 4.0 & $3.4-4.7$ & 450 & 1.0 & $0.9-1.1$ \\
\hline First primary HR-positive & 6,129 & & & 25,735 & & \\
\hline Any second primary & 51 & 2.2 & $1.7-2.9$ & 248 & 0.8 & $0.7-0.9$ \\
\hline Second primary HR-positive & 25 & 1.7 & $1.2-2.5$ & 139 & 0.6 & $0.5-0.7$ \\
\hline Second primary HR-negative & 7 & 1.8 & $0.8-3.5$ & 43 & 1.0 & $0.8-1.4$ \\
\hline Second primary HR-mixed & 11 & 4.8 & $2.5-8.4$ & 38 & 1.0 & $0.7-1.4$ \\
\hline First primary HR-negative & 1,895 & & & 4,758 & & \\
\hline Any second primary & 60 & 9.2 & 7.1-11.9 & 104 & 2.0 & $1.7-2.5$ \\
\hline Second primary HR-positive & 8 & 2.6 & $1.4-4.5$ & 31 & 0.9 & $0.7-1.3$ \\
\hline Second primary HR-negative & 33 & 25.4 & $17.6-35.4$ & 46 & 6.1 & $4.5-8.1$ \\
\hline Second primary HR-mixed & 12 & 18.1 & $9.6-31.1$ & 12 & 2.3 & $1.3-3.7$ \\
\hline
\end{tabular}

O: observed number of cases; SIR: standardized incidence ratio; $95 \% \mathrm{Cl}$ : $95 \%$ confidence interval; HR, hormone receptor. 
status of FBC. We observed a lower SIR of HR-positive $\mathrm{CBC}$ among women with $\mathrm{HR}$-positive $\mathrm{FBC}$ while in women with HR-negative FBC the SIR of HR-negative $\mathrm{CBC}$ was considerably increased. Among women with first primary cancer diagnosed before the age of 50 years, the estimate of developing $\mathrm{CBC}$ was increased, and this increase was especially pronounced in HRnegative $\mathrm{FBC}$.

As reported by previous studies, the HR status of $\mathrm{CBC}$ can be more similar to the HR status of FBC than would be expected by chance due to host factors. That leads to the assumption that particular women are more likely to have cancers of a certain HR subtype $[17,18]$. The concordance in HR subtype may be the result of common genetic and non-genetic factors that influenced the development of FBC of a particular HR subtype as well as the second primary occurrence of the same subtype in the contralateral breast [19].

Our results are in accordance to previous populationbased studies that reported SIRs from about 5 to 10 for developing HR-negative $\mathrm{CBC}$ among women with HRnegative first primary [6-8]. On the one hand, limited relative effectiveness of chemotherapy and radiotherapy, and limited understanding of relevant targets in treatment of HR-negative breast cancer may have led to that particularly increased risk [20]. On the other hand, genetic and non-genetic factors causing HR-negative primaries may be relatively stronger compared to host factors causing HR-positive primaries.

With reference to previously published studies, results of developing HR-positive CBC after HR-positive FBC remain contradictory. While Kurian et al. and Sandberg et al. reported increased SIRs, the study of Bouchardy et al. and ours observed decreased SIRs [6-8]. That decrease may reasonably be linked to adjuvant hormonal treatment used among women with HR-positive FBC. It is well known that hormone treatment with tamoxifen reduces the risk of CBC $[4,21,22]$. This protective effect may affect cells with carcinogenic potential in the contralateral breast. Tamoxifen treatment was introduced in German guidelines in 1995. An unselected retrospective cohort study including 2,600 breast cancer patients with universal coverage in the catchment area of the Federal State of Baden-Württemberg over a 13-year observation period (1992 to 2005) reported that around 90\% of endocrineresponsive patients received an adjuvant hormonal treatment since 1999 [23]. Our observations provide no strong evidence that tamoxifen treatment may increase the risk of HR-negative CBC after HR-positive FBC [5]. The increased SIR of developing HR-positive CBC after HR-positive FBC reported by Kurian et al. may reflect the disparities in the ability to afford hormone treatment of different ethnic groups in the U.S. [6]. The result of Sandberg et al. analyzing the period 1976 to 2005 may be due to the established use of tamoxifen treatment only in the last decade of observation [8].

In this study, approximately $10 \%$ of $\mathrm{FBC}$ had mixed HR status. Women with HR-mixed FBC showed an increased risk of CBC overall, and especially of HR-mixed CBC. Although hormone treatment with tamoxifen is used to treat both subtypes (ER+PR- and ER-PR+), it tends to be less effective for ER-PR+. ER status seems to be the only factor importantly predictive for reductions of breast cancer recurrence and death [24]. Furthermore, Arpino et al. assumed that lack of PR in ER-positive breast cancer may be an indicator of abnormal growth factor signaling, which could add to resistance in tamoxifen treatment. They noticed a poorer survival in tamoxifentreated women with ER+ PR- than in such women with $\mathrm{ER}+\mathrm{PR}+$. Our finding of an increased risk of $\mathrm{CBC}$ after HR-mixed FBC may implicate those aspects [25].

Early age at first diagnosis is a well-known risk factor for CBC [2]. It has been also reported in the context of a positive family history of breast cancer and among BRCA1 and BRCA2 mutation carriers [26,27]. This suggests that more genetic than non-genetic factors may contribute to these cases and women may be more susceptible to cancer developing in both breasts. In particular, we showed a markedly increased risk of HR-negative $\mathrm{CBC}$ in women with age lower than 50 years, which is in line with reports that observed that the majority of BRCA-associated breast cancers were HR-negative and concordant in first and second primary [28-30].

The pooling of the cancer registries' data enabled us to estimate SIRs of CBC in detail. Nevertheless, there are factors limiting the interpretation of our results. First, although this study provides the largest number of FBC patients at risk for $\mathrm{CBC}$ by $\mathrm{HR}$ status in Europe, we still suffer from small numbers of $\mathrm{CBC}$, especially in detailed analysis by HR subtype. Second, the median years of follow-up of about three years seems to be short. However, previous studies showed no effect for time since primary diagnosis on risk for $\mathrm{CBC}$ by HR status $[6,8]$. Third, there is a lack of stage and treatment information, particularly to assess the influence of adjuvant hormonal treatment on risk of developing $\mathrm{CBC}$ after HR-positive FBC. However, we assume that almost all women with HR-positive FBC received adjuvant hormone treatment based on the introduction of treatment with tamoxifen in German guidelines in 1995. Available German study results underline this assumption [23]. Finally, misclassification of HR status by differences in for example tissue fixation, choice of antibody, scoring method and type of assay could have affected SIRs. Several reports documented an interobserver and interlaboratory variation for radioimmunoassay and immunohistochemical assay $[31,32]$. The HR status of the analyzed cases was predominantly determined by immunostains. 


\section{Conclusions}

HR status and age at diagnosis of breast cancer are modifiers for risk of $\mathrm{CBC}$. Women with HR-negative FBC have an increased risk of all HR subtypes in $\mathrm{CBC}$, and specifically of HR-negative. Our findings support, among these women with age lower than 50 years at FBC diagnosis, the recommendation of intensive followup and surveillance for secondary prevention of cancer in the contralateral breast.

\section{Additional file}

Additional file 1: Pooling Brandenburg, Munich and Saarland,

1998-2007. Table S1. Shows standardized incidence ratios of

metachronous contralateral breast cancer stratified by estrogen receptor

(ER)-status. Table S2. Shows standardized incidence ratios of

metachronous contralateral breast cancer stratified by hormone receptor (HR)-status excluding cases with missing HR status.

\section{Abbreviations}

95\%Cl: 95\% confidence interval; BB: cancer registry of the Federal State of Brandenburg; $\mathrm{CBC}$ : contralateral breast cancer; E: number of expected cases; ER: estrogen receptor; FBC: first primary breast cancer; HER2: human epidermal growth factor receptor 2; HR: hormone receptor; MCR: Munich Cancer Registry; O: number of observed cases; PR: progesterone receptor; SIR: standardized incidence ratio; SL: Saarland Cancer Registry.

\section{Competing interests}

The authors declare that they have no competing interests.

\section{Authors' contributions}

CR and AS were responsible for the conception, design, analysis, interpretation and preparation of the manuscript. KW contributed to analysis, interpretation and preparation of the manuscript. UBG, JE, CS, BH, GSF and AT provided data and contributed to the preparation of the manuscript by critically revising it. All authors read and approved the final manuscript.

\section{Acknowledgements}

This work was supported by grants of the Deutsche Forschungsgemeinschaft (DFG) (grant-number STA 621/4-1, BA 4021/1-1, EN 888/1-1, STE 1873/1-1)

\section{Author details}

${ }^{1}$ Institute of Clinical Epidemiology, Medical Faculty, Martin-Luther-University of Halle-Wittenberg, Magdeburger Strasse 8, 06097 Halle (Saale), Germany. ${ }^{2}$ Cancer Registry of the Federal State of Brandenburg, Müllroser Chaussee 7, 15236 Frankfurt (Oder), Germany. ${ }^{3}$ Munich Cancer Registry of the Munich Cancer Centre, Clinic Großhadern/IBE, Ludwig-Maximilians-University Munich, Marchioninistrasse 15, 81377 Munich, Germany. ${ }^{4}$ Saarland Cancer Registry, Präsident-Baltz-Strasse 5, 66119 Saarbrücken, Germany. ${ }^{5}$ Department of Epidemiology, School of Public Health, Boston University, 715 Albany Street, Boston, MA 02118, USA.

Received: 14 May 2014 Accepted: 26 September 2014

Published online: 03 October 2014

\section{References}

1. Veronesi U, Boyle P, Goldhirsch A, Orecchia R, Viale G: Breast cancer. Lancet 2005, 365:1727-1741.

2. Chen Y, Thompson W, Semenciw R, Mao Y: Epidemiology of contralateral breast cancer. Cancer Epidemiol Biomarkers Prev 1999, 8:855-861.

3. Malone KE, Begg CB, Haile RW, Borg A, Concannon P, Tellhed L, Xue S, Teraoka S, Bernstein L, Capanu M, Reiner AS, Riedel ER, Thomas DC, Mellemkjaer L, Lynch CF, Boice JD Jr, Anton-Culver H, Bernstein JL: Population-based study of the risk of second primary contralateral breast cancer associated with carrying a mutation in BRCA1 or BRCA2. J Clin Oncol 2010, 28:2404-2410.
4. Early Breast Cancer Trialists' Collaborative Group: Tamoxifen for early breast cancer: an overview of the randomised trials. Lancet 1998, 351:1451-1467.

5. Li Cl, Malone KE, Weiss NS, Daling JR: Tamoxifen therapy for primary breast cancer and risk of contralateral breast cancer. J Natl Cancer Inst 2001, 93:1008-1013.

6. Kurian AW, McClure LA, John EM, Horn-Ross PL, Ford JM, Clarke CA: Second primary breast cancer occurrence according to hormone receptor status. J Natl Cancer Inst 2009, 101:1058-1065.

7. Bouchardy C, Benhamou S, Fioretta G, Verkooijen HM, Chappuis PO, Neyroud-Caspar I, Castiglione M, Vinh-Hung V, Vlastos G, Rapiti E: Risk of second breast cancer according to estrogen receptor status and family history. Breast Cancer Res Treat 2011, 127:233-241.

8. Sandberg ME, Hall P, Hartman M, Johansson AL, Eloranta S, Ploner A, Czene K: Estrogen receptor status in relation to risk of contralateral breast cancer-a population-based cohort study. PLoS One 2012, 7:e46535.

9. Arbeitsgruppe Erhebung und Nutzung von Sekundärdaten und Arbeitsgruppe Epidemiologische Methoden: Good practice of secondary data analysis, first revision. Gesundheitswesen 2008, 70:54-60

10. Curado MP, Edwards B, Shin HR, Storm H, Ferlay J, Heanue M, Boyle P: Cancer in Five Continents Vol. IX. Lyon: IARC Press; 2007.

11. Gesellschaft für epidemiologische Krebsregister in Deutschland e.V. und das RKI: Krebs in Deutschland, 7. Saarbrücken: Ausgabe; 2010

12. World Health Organization: The International Statistical Classification of Diseases and Related Health Problems, Tenth revision. Geneva: World Health Organization; 1992.

13. Fritz A, Percy C, Jack A, Shanmugaratnam K, Sobin L, Parkin DM, Whelan S: International Classification of Diseases for Oncology (ICD-O). 3rd edition. Geneva: World Health Organization; 2000.

14. Klebanoff MA, Cole SR: Use of multiple imputation in the epidemiologic literature. Am J Epidemiol 2008, 168:355-357.

15. Janssen KJ, Donders AR, Harrell FE Jr, Vergouwe Y, Chen Q, Grobbee DE, Moons KG: Missing covariate data in medical research: to impute is better than to ignore. J Clin Epidemiol 2010, 63:721-727.

16. Little RJA, Rubin DB: Statistical Analysis with Missing Data (Second Edition). New York: John Wiley \& Sons; 2002

17. Swain SM, Wilson JW, Mamounas EP, Bryant J, Wickerham DL, Fisher B, Paik S, Wolmark N: Estrogen receptor status of primary breast cancer is predictive of estrogen receptor status of contralateral breast cancer. J Natl Cancer Inst 2004, 96:516-523.

18. Sandberg ME, Hartman M, Klevebring D, Eloranta S, Ploner A, Hall P, Czene K Prognostic implications of estrogen receptor pattern of both tumors in contralateral breast cancer. Breast Cancer Res Treat 2012, 134:793-800.

19. Saltzman BS, Malone KE, McDougall JA, Daling JR, Li Cl: Estrogen receptor, progesterone receptor, and HER2-neu expression in first primary breast cancers and risk of second primary contralateral breast cancer. Breast Cancer Res Treat 2012, 135:849-855.

20. Eiermann W, Bergh J, Cardoso F, Conte P, Crown J, Curtin NJ, Gligorov J, Gusterson B, Joensuu H, Linderholm BK, Martin M, Penault-Llorca F, Pestalozzi BC, Razis E, Sotiriou C, Tjulandin S, Viale G: Triple negative breast cancer: proposals for a pragmatic definition and implications for patient management and trial design. Breast 2012, 21:20-26.

21. Early Breast Cancer Trialists' Collaborative Group (EBCTCG): Effects of chemotherapy and hormonal therapy for early breast cancer on recurrence and 15-year survival: an overview of the randomised trials. Lancet 2005, 365:1687-1717.

22. Phillips KA, Milne RL, Rookus MA, Daly MB, Antoniou AC, Peock S, Frost D, Easton DF, Ellis $S$, Friedlander ML, Buys SS, Andrieu N, Noguès $C$, Stoppa-Lyonnet D, Bonadona V, Pujol P, McLachlan SA, John EM, Hooning MJ, Seynaeve C, Tollenaar RA, Goldgar DE, Terry MB, Caldes T, Weideman PC, Andrulis IL, Singer CF, Birch K, Simard J, Southey MC, et al: Tamoxifen and risk of contralateral breast cancer for BRCA1 and BRCA2 mutation carriers. J Clin Oncol 2013, 31:3091-3099.

23. Van Ewijk RJ, Schwentner L, Wockel A, Konig J, Kreienberg R, Blettner M: Trends in patient characteristics, treatment and survival in breast cancer in a non-selected retrospective clinical cohort study of 2,600 patients. Arch Gynecol Obstet 2013, 287:103-110.

24. Davies C, Godwin J, Gray R, Clarke M, Cutter D, Darby S, McGale P, Pan HC, Taylor C, Wang YC, Dowsett M, Ingle J, Peto R: Relevance of breast cancer hormone receptors and other factors to the efficacy of adjuvant tamoxifen: patient-level meta-analysis of randomised trials. Lancet 2011, 378:771-784. 
25. Arpino G, Weiss H, Lee AV, Schiff R, De PS, Osborne CK, Elledge RM: Estrogen receptor-positive, progesterone receptor-negative breast cancer: association with growth factor receptor expression and tamoxifen resistance. J Natl Cancer Inst 2005, 97:1254-1261.

26. Metcalfe K, Lynch HT, Ghadirian P, Tung N, Olivotto I, Warner E, Olopade Ol, Eisen A, Weber B, McLennan J, Sun P, Foulkes WD, Narod SA: Contralateral breast cancer in BRCA1 and BRCA2 mutation carriers. J Clin Oncol 2004, 22:2328-2335.

27. Graeser MK, Engel C, Rhiem K, Gadzicki D, Bick U, Kast K, Froster UG, Schlehe B, Bechtold A, Arnold N, Preisler-Adams S, Nestle-Kraemling C, Zaino M, Loeffler M, Kiechle M, Meindl A, Varga D, Schmutzler RK: Contralateral breast cancer risk in BRCA1 and BRCA2 mutation carriers. J Clin Oncol 2009, 27:5887-5892.

28. Lakhani SR, Van De Vijver MJ, Jacquemier J, Anderson TJ, Osin PP, McGuffog L, Easton DF: The pathology of familial breast cancer: predictive value of immunohistochemical markers estrogen receptor, progesterone receptor, HER-2, and $\mathrm{p} 53$ in patients with mutations in BRCA1 and BRCA2. J Clin Oncol 2002, 20:2310-2318.

29. Weitzel JN, Robson M, Pasini B, Manoukian S, Stoppa-Lyonnet D, Lynch HT, McLennan J, Foulkes WD, Wagner T, Tung N, Ghadirian P, Olopade O, Isaacs C, Kim-Sing C, Moller P, Neuhausen SL, Metcalfe K, Sun P, Narod SA: A comparison of bilateral breast cancers in BRCA carriers. Cancer Epidemiol Biomarkers Prev 2005, 14:1534-1538.

30. Nilsson MP, Hartman L, Idvall I, Kristoffersson U, Johannsson OT, Loman N: Long-term prognosis of early-onset breast cancer in a population-based cohort with a known BRCA1/2 mutation status. Breast Cancer Res Treat 2014, 144:133-142

31. Sluyser $\mathrm{M}$, Wittliff $\mathrm{J}$ : Influence of estrogen receptor variants in mammary carcinomas on the prognostic reliability of the receptor assay. Mol Cell Endocrinol 1992, 85:83-88.

32. Rhodes A, Sarson J, Assam EE, Dean SJ, Cribb EC, Parker A: The reliability of rabbit monoclonal antibodies in the immunohistochemical assessment of estrogen receptors, progesterone receptors, and HER2 in human breast carcinomas. Am J Clin Pathol 2010, 134:621-632.

doi:10.1186/s13058-014-0452-4

Cite this article as: Rusner et al:: Risk of contralateral second primary

breast cancer according to hormone receptor status in Germany. Breast Cancer Research 2014 16:452.

\section{Submit your next manuscript to BioMed Central and take full advantage of:}

- Convenient online submission

- Thorough peer review

- No space constraints or color figure charges

- Immediate publication on acceptance

- Inclusion in PubMed, CAS, Scopus and Google Scholar

- Research which is freely available for redistribution 